\title{
Emerging Antimicrobial Resistance and Evolving Healthcare: Dangerous Crossroads for the Community and the Military
}

\author{
Inam Danish Khan, ${ }^{1,}{ }^{*}$ Rajiv Mohan Gupta, ${ }^{2}$ Sourav Sen, ${ }^{3}$ KS Rajmohan, ${ }^{4}$ Ashok Kumar Jindal, ${ }^{5}$ \\ Anuradha Makkar, ${ }^{6}$ Fashiur Rahman Razi, ${ }^{7}$ Priyanka Banerjee, ${ }^{8}$ Pragyan Panda, ${ }^{8}$ G. Lakshmi Nair, ${ }^{9}$ \\ Kanchan Kulhari, ${ }^{10}$ and Shilpi Singh ${ }^{11}$ \\ ${ }^{1}$ Asst Professor Clinical Microbiology and Infectious Diseases, Army College of Medical Sciences and Base Hospital, Delhi Cantt 110010 India \\ ${ }^{2}$ Consultant and Professor Microbiology, Army Hospital (R \& R), New Delhi 110001, India \\ ${ }^{3}$ Professor and Head Microbiology, Armed Forces Medical College, Pune 411040 India \\ ${ }^{4}$ Senior Advisor and Head Pathology, Base Hospital and Army College of Medical Sciences, Delhi Cantt 110010 India \\ ${ }^{5}$ Professor Community Medicine, Armed Forces Medical College, Pune 411040 India \\ ${ }^{6}$ Professor and Head Microbiology, Army College of Medical Sciences and Base Hospital, Delhi Cantt 110010 India \\ ${ }^{7}$ Pharmacist, Allana College of Pharmacy, Pune, India \\ ${ }^{8}$ Asst Professor Microbiology, Army College of Medical Sciences and Base Hospital, Delhi Cantt 110010 India \\ ${ }^{9}$ Asst Professor Pathology, Army College of Medical Sciences and Base Hospital, Delhi Cantt 110010 India \\ ${ }^{10}$ Asst Professor Biochemistry, Army College of Medical Sciences and Base Hospital, Delhi Cantt 110010 India \\ ${ }^{11}$ Asst Professor Microbiology, Army Hospital (R \& R), New Delhi 110001, India \\ "Corresponding author: Major Dr Inam Danish Khan, Dept of Pathology, Base Hospital, Delhi Cantt 110010. Tel: +91-9836569777, E-mail: titan_afmc@yahoo.com
}

Received 2017 April 25; Revised 2017 September 13; Accepted 2017 September 17.

\begin{abstract}
Modern diagnostic and therapeutic procedures including advanced surgeries, organ transplants, and immunotherapy are pillared by antimicrobial therapy. Parallel to the rising incidence of infectious diseases, the menace of antimicrobial resistance (AMR) emerged worldwide. Developing countries are facing the brunt in epidemic proportions due to huge population, substandard housing, overcrowding, rapid unplanned urbanization, deterioration in water and waste management systems, strained public health infrastructure, and limited resource allocation to healthcare. Simultaneously, AMR has adversely affected the outcome of military injuries. The rising problem of AMR is discouraging the development of newer antimicrobials by the pharmaceutical industry. There has been a considerable impetus towards concept development; however, the magnitude of the problem overshadows the progress made towards the control of AMR worldwide. There is a dire need to identify this threat, develop concerted multipronged strategy, develop infrastructure, foster expertise, and take coordinated and urgent steps to tackle the serious public health challenge. An intensified commitment needs to be taken up on a war footing at individual, local, national, regional, and international levels. This article discusses the overall concept for developing countries.
\end{abstract}

Keywords: Antimicrobial Resistance, Panresistance, Totally Drug Resistant Tuberculosis, Hospital Infection Control, Antimicrobial Stewardship

\section{Introduction}

The sojourn of human health spans from the extermination of billions attributable to plague, cholera, influenza, smallpox, measles, and malaria to the evolution of modern healthcare extending health security to billions through leading-edge research- and technologydriven solutions. There was no reliable solution to infectious diseases until the discovery of penicillin in 1940s, which formed a major breakthrough in the history of humankind. There was a stark contrast in the outcome of wounded military personnel due to lives saved from infection and sepsis in World War II compared to World War I. Along with subsequently discovered antimicrobials in the next three decades, considerable confidence was insti- tuted in antimicrobial-based treatment of infectious diseases. The acclaimed success not only boosted patient care, but also furthered the development of advanced surgeries, organ transplants, and immunotherapy, being heavily dependent on antimicrobial support.

Nevertheless, the re-emergence of infectious diseases and the associated phenomenon of antimicrobial resistance (AMR) were unanticipated in its entirety. Since 1980 s, the resurgence of infectious diseases consequent to the advent of HIV-AIDS pandemic resulted in 1.5 fold increase in death rate from infectious diseases between 1980 and 1992 (1). With the continuing HIV-AIDS pandemic and growth of organ transplantation, a gradually rising immunocompromised populace has emerged with special protection requirements against infectious diseases. AMR has become 
a gradually progressive phenomenon reaching immense proportions beyond control. World health organization (WHO) selected the theme for world health day 2011 as "Antimicrobial resistance: no action today, no cure tomorrow" (2-4). There has been a considerable impetus towards concept development; however, the magnitude of the problem overshadows the progress made towards the control of AMR worldwide $(4,5)$.

The military health system has been adversely affected by AMR leading to loss of soldiers sustaining war injuries at the battlefront. Injuries sustained in war and conflict scenarios such as gunshots, mine-blast injuries, and grenadeexplosions have led to extensive tissue devitalization predisposing to health-care associated infections with multidrug resistant (MDR) organisms in wounded military personnel (6-8). Military personnel can be colonized by multidrug resistant pathogens after exposure to military deployments (9). Wounds sustained in military settings not attributable to direct war injuries are also predisposed to similar infections (10). This article discusses the problem of AMR along with potential control strategies in the developing world perspective.

\section{Evolution of Antimicrobial Resistance}

The rise of AMR to high proportions is a multifactorial phenomenon under a vicious cycle. Firstly, there is an increase in susceptible hosts living in conditions such as immunodeficiency disorders, organ transplantations, neoplasms, and metabolic disorders, as well as patients under intensive care. Secondly, natural evolution of microorganisms confers an increase in virulence, stability, transmissibility, infectivity, pathogenicity, and antimicrobial resistance. Organisms not known to be pathogenic earlier are now being encountered as opportunistic pathogens (1, 11-13). Established pathogens are evolving into potentially untreatable multiresistant mutants such as methicillin resistant Staphylococcus aureus (MRSA), Methicillin Resistant Coagulase negative Staphylococcus (MR-CONS), Vancomycin Resistant Staphylococcus aureus (VRSA), vancomycin resistant Enterococci (VRE), Extended Spectrum Beta Lactamase (ESBL) Gram negative bacteria, Carbapenem Resistant Enterobacteriaceae (CRE), and pan drug resistant (PDR) gram negative bacteria, which are resistant to all available antimicrobials. In addition, totally drug resistant tuberculosis (TDR TB), MDR malaria, dual oseltamivir-adamantane resistant influenza viruses, antiretroviral resistant HIV, antiherpes resistant herpesviruses as well as multiresistant fungi are emerging $(14,15)$. Thirdly, the patients harbouring multiresistant microorganisms are aggressively exposed to multiple antimicrobials. Spiralling empiricism in antimicrobial therapy overshadows susceptibility-guided therapy, facilitating the development of further resistance due to selection pressure in the backdrop of persistent infections. Approximately $25 \%$ - 33\% of hospitalized patients receive antimicrobials and $22 \%-65 \%$ of antimicrobial usage has been found to be inappropriate $(16,17)$. Fourthly, these resistance microorganisms can spread the resistance-conferring genetic elements to hitherto susceptible microorganisms, contributing to the development of a reservoir of antimicrobial resistance in microflora. Further adding to the problem is the spread of these resistance microorganisms in healthcare facilities thereby rendering all patients and providers at-risk. Human factors involved include a complex interplay of antimicrobial misuse due to lack of regulatory commitment in the backdrop of natural mutations, which has contributed to the development of $\operatorname{AMR}(1,3,4)$.

The resistance of Staphylococcus aureus to penicillin was first reported in 1947, followed by methicillin resistance (MRSA) in 1961, vancomycin resistance in 2002 and linezolid resistance in 2003 (18). MRSA is now widespread in hospital and community environments worldwide (19). Similarly, penicillin resistance in Streptococcus pneumoniae and macrolide resistance in Streptococcus pyogenes are now widespread (20). 21 Resistance of Enterococci to penicillin was reported in 1983, to vancomycin in 1987, and to linezolid in 1990s. Clostridium difficile has been reported resistant to clindamycin and fluoroquinolones (21). "Plasmid encoding carbapenem resistant metallo-beta-lactamase" has been observed in Escherichia coli and Klebsiella pneumonia (22). PDR is increasingly being reported in Gramnegative microbes (23).

The military health system has been plagued by emergence of MDR gram negative pathogens such as Acinetobacter baumanii and Klebsiella pneumoniae that contribute to sepsis-induced mortality. During the Soviet-Afghanistan War, the incidence of wound sepsis was 5.4\% with 9.3\% survival (24). Sepsis led to $15.51 \%$ and $37.7 \%$ deaths in Syrian Civil War and Philippines, respectively (25). MDR bacteria were found in evacuated military personnel from Afghanistan and Iraq (26-29).

Acinetobacter-induced sepsis has a negative prognosis with $20 \%-60 \%$ mortality (30). 100 cases of MDR were encountered in operation enduring freedom and two panresistant Acinetobacter blood stream infections meeting the CDC's national nosocomial infection surveillance criteria were encountered during operation Iraqi Freedom. Acinetobacter, quoted as the 'military superbug' and 'Iraqibacter', has been included under the US Military 'Global Emerging Infections Surveillance' program (31-33).

The South and South-East Asia region (SEAR) has one of 
the highest numbers of TB cases with one death every few minutes (34). All forms of resistant tuberculosis, viz. Multi drug resistant tuberculosis (MDR TB), extremely drug resistant tuberculosis (XDR TB) and totally drug resistant tuberculosis (TDR TB), have been reported from the region. The recent reports of TDR TB from Iran, India, and Italy represent the tip of an iceberg as antitubercular susceptibility testing occurs in only $5 \%$ of TB cases worldwide. The emergence of tuberculosis as the world's largest killer amongst infectious diseases surpassing HIV in 2014 - 15 reflects the scourge of tuberculosis upon the future of health systems worldwide (34-37). The DOTS (Directly observed Treatment Short course) program for developing countries has been challenged by the emergence of XDR TB and TDR TB. The introduction of DOTS plus for MDR and XDR TB is limited by susceptibility testing and thus can be offered only at highly specialized centres. A seven-year study on DOTS plus reported $61 \%$ cure, $19 \%$ deaths, $18 \%$ defaulters, $3 \%$ failed treatments and an average delay of 5 months in initiation of therapy (38).

While MDR malaria is widespread, resistance to newer drugs such as artemisinin has also been reported in SEAR (39). Candida and Cryptococcus have developed resistance to azoles, 5-flucytosine, amphotericin B, and echinocandins. Antiviral resistance to almost all antivirals has been reported particularly in Hepatitis B, Herpes virus, Cytomegalovirus, Varicella zoster, Influenza, and HIV (40).

No new antimicrobial agent until date has stood the test of time. While exceptional antimicrobials such as nitrofurantoin, erythromycin, and vancomycin have remained effective for more than three decades, the time between deployment of antimicrobials and development of resistance has been observed to be as low as few years for tetracycline, methicillin, linezolid, and daptomycin. Resistance to sulphonamides and penicillin was reported as early as 1940 s followed by resistance to other antimicrobials subsequently (41).

\section{Impact of Antimicrobial Resistance}

The resurgence of drug resistant emerging infectious diseases is becoming a public health problem worldwide. Developing countries are facing the brunt in epidemic proportions due to huge population, strained public health infrastructure, and limited resource allocation to healthcare.

No new class of antimicrobials has been added since $1987(1,42)$. Antimicrobials are used intermittently and any new molecule loses economic value in a few years due to emergence of resistance. The pharmaceutical industry is directing resources for lifestyle diseases as they have more economic value $(43,44)$.
MDR/PDR superbugs can be exploited as agents of bioterrorism. Given the ease of maintenance, dispersion, and person-to-person transmission, they may be clandestinely deployed by state or non-state agencies against humans, fauna, and flora. Inadvertent or intended release of modified organisms is a possible after-effect of bioterrorism (45).

\section{The Way Forward}

AMR is a biological, behavioural, technical, economic, regulatory, and educational problem of global concern and combating it requires concerted efforts at the national and global levels. The stakeholders include planners and policy makers, public, patients, practitioners, pharmacists, and pharmaceutical industry. An intensified commitment needs to be taken up on a war footing at individual, local, national, regional, and international levels (46).

\section{Individual Level}

\subsection{Knowledge, Attitude, Practices, and Behaviour of public}

There is an urgent need for public to be knowledgeable about approach, operation, decision making, and scope of healthcare. Attitude and expectations should be changed from "instant cure" and "magic pill" to "rational drug therapy" and "evidence-based healthcare". Up to $50 \%$ of patients may have poor compliance (47). Selfmedication, quack remedies, underdosing, uncompleted regimens, and frequent change of doctor's advice should be stopped. Left over drugs from the last prescription should not be taken again for a similarly perceived symptom. Patients should avoid requests or arguments and not exhibit impatience or arrogance based on hearsay without adequate knowledge. Citizens must foster sound belief and inculcate positive attitude and responsible behaviour in societal healthcare system.

\section{Responsible Drug Dispensing}

Antimicrobials may be freely available in pharmacies without prescription due to unavailability of pharmacists, insufficient training, lack of legislation, and community demands. Pharmacies and chemists should not dispense antimicrobials without prescription.

\subsection{Hand Hygiene}

Hand washing is considered the single most important step in controlling spread of MDR pathogens. Unfortunately, it is missed out due to overbearing pressures of patient volume, time, and undue multitasking. Availability 
of washing infrastructure is also a constraint in limited resource health settings. Hand washing with soap followed by antiseptic hand rub should be strongly encouraged as the standard of care for all healthcare practitioners and patients (48).

\section{Responsible Healthcare Delivery}

While the state sponsored healthcare promotes baseline antimicrobials, there is a growing use of higher generation antimicrobials in the private sector. This is partly because of request from patients, unethical marketing by drug manufacturers and prescription by practitioners.

\section{Hospital Level}

\subsection{Clinical Microbiology Laboratories}

The microbiology laboratory plays a key role in conducting lab-based surveillance of infectious diseases, pathogens, susceptibility patterns, resistance phenotyping, outbreak investigation, and epidemiological typing in addition to hospital environmental surveillance (49, 50). With the advent of automated systems, molecular microbiology techniques and biostatistical software, precise pathogen identification, antimicrobial resistance phenotypes and typing have been facilitated. Resistant phenotypes can be included in microbial type culture collection facilities. Clinical expertise combined with computerized decision support technology can facilitate targeted antimicrobial treatment, assess prognosis, check the development of antimicrobial resistance, and guide infection control policies. The laboratory can be linked to other WHO Collaborating Centers to share resistograms through a worldwide web repository. The potential of the microbiology lab is largely underutilized in developing countries due to deficiencies in lab infrastructure and work force.

\section{Antimicrobial Stewardship}

Antimicrobial stewardship including antimicrobial rotation and holiday, combination therapy, escalationdeescalation, and standard treatment guidelines has been proven beneficial $(51,52)$. Spiralling empiricism, prophylactic antimicrobial usage, and attitude to use the best antimicrobial agent should be discouraged and susceptibility guided therapy needs to be promulgated (1). Regular availability of required antimicrobials, prescription audits, formulary restriction, pre-authorization, and stop orders should be advocated to ensure policy implementation, which in turn should be linked to grant of accreditation to hospitals. A multidisciplinary approach would include building of consensus across clinicians and arbitration of disagreements.

\section{Hospital Infection Control}

Hospital infection control committee plays a multidimensional role in hospital safety measures such as patient isolation, visitor control, contact precautions, barrier nursing, universal prophylaxis, hand hygiene, and equipment sterilization, thereby reducing the incidence of MDR nosocomial infections. Surveillance of air, water, food, surfaces, medical devices, disinfectants, and staff along with linen disinfection and hospital waste disposal is ensured $(53,54)$. Carriers are identified, quarantined, and pathogens are eradicated from hospital environment. Various national and international bodies have promulgated infection control guidelines (55-57). CDC-USA has instituted isolation precautions guidelines specific for tuberculosis and professional hazards (58-62). The military health system needs to incorporate hospital-based surveillance and face the burden of antimicrobial resistance leading to loss of lives from injuries sustained at the battlefront (21, 63).

\section{Industry Level}

\subsection{Agriculture, Poultry, Livestock, and Fisheries}

Unregulated antimicrobial use to enhance farm yield of poultry, livestock, swine, fish, and bee farming is estimated to be 1000 fold greater in terms of absolute tonnage compared to human consumption, hugely contributing to the development of AMR. There is a dire need for regular farm audit and vigilance along with legislated correctional measures to curb antimicrobial abuse. The European Union has banned antimicrobial growth promotion in livestock (64).

\section{Veterinary practice and Animal Husbandry}

Antimicrobial regimens in veterinary practice are not standardized. The US Food and Drug Administration has recently phased out unsupervised use of drugs as feed additives and converted approved over the counter antimicrobials to veterinary prescription only. Removal of avoparcin use in swine and chicken farming in European Union has led to reduction in resistance (65). There is a need for collaboration and vigilance in the veterinary sector to discourage non-therapeutic use of antimicrobials 
and courage the use of standard treatment guidelines (STGs) in veterinary practice and animal husbandry.

\section{Cosmetic and Chemical Industry}

Usage of low dose antimicrobials in cosmetics and chemicals targeted at preventing product contamination largely remains undetected. Regular monitoring of fresh batches by concerned drug controlling authority is necessitated.

\section{Pharmaceutical industry}

The pharmaceutical industry is opportunity driven. Unjust manufacturing practices are contributing to AMR. Higher revenues are generated in producing higher generation 'wonder drugs' and marketing them to the patientfront healthcare (9). Audit and vigilance for Good Manufacturing Practices and responsible marketing are a requisite.

\section{National Level}

\subsection{Health Resource Allocation and Commitment}

The present situation demands an increase in resource allocation in the health sector to boost healthcare infrastructure, public awareness, and accessibility. This would entail liberal and accommodative policy for establishment of specialized medical varsities, superspeciality hospitals, specialized laboratories, biocontainment facilities, promotion of antimicrobial research through grants, involvement of private sector through public private partnership, subsidies for health industry, and mass health campaigns. An unfettered commitment through enhancing participation of apex planners, health officials, healthcare providers, patients, administrative appointees, industry personnel, and public is mandated. Comprehensive standards for surveillance and control should be established in association with international health regulations (64). National surveillance systems similar to the national nosocomial infection surveillance (NNIS) in the US and SENTRY antimicrobial surveillance program can be instituted (66). National guidelines on infection control, antimicrobial therapy, and health policy need to be reiterated in appropriate media and for a (67).

\section{Enhancing Lab Capacity}

A number of pathogens surpass identification under the constraints of resources available in routine laboratories $(1,46)$. Susceptibility testing for tuberculosis, parasites, viruses, and fungi is only available in reference labs that are far and few. Unavailability of testing facilities promotes empirical antimicrobial therapy, thereby contributing to the development of AMR. An enhanced lab capacity will facilitate rapid and reliable detection of pathogens and antimicrobial susceptibility, which can direct targeted antimicrobial therapy.

\section{Public Health Measures}

Improving health, hygiene, and sanitation at community level may improve general health and reduce source and transmission of infectious diseases. Robust public health infrastructure with strengthened vector control programs, immunization, reproductive health, disease screening, laboratory-based surveillance, outbreak investigation, quarantine, and control measures are required. Healthcare accessibility can be improved with free or easy availability of basic drugs, antimicrobials, and contraceptives. MDR/PDR pathogens should be made notifiable. Effective public health will reduce reliance on antimicrobials and break the chain of transmission of resistant microbes (43).

\section{Education and Health Campaigns}

STGs, hospital infection control, and AMR surveillance should be included in the syllabi of medical, nursing, laboratory, paramedical, biotechnology, health management, and doctorate courses. School and college curricula should also emphasize the topic. Medical societies, journals, and mass media can collaborate to spread awareness campaigns such as "Antibiotics are not automatic" in France, "Get Smart" in US and “Do Bugs need Drugs?" in Canada (68, $69)$.

\section{Legislation}

Quality assurance in antimicrobial dosage and efficacy from manufacturers, ethical marketing, and quack practices are significant problems. There is a need for educating pharmacists regarding the hazard of selling antimicrobials without prescription. Regulatory mechanisms for ensuring good manufacturing practices, responsible marketing, dispensation by pharmacists, preventing antimicrobial abuse by individuals and proper hospital waste disposal need to be instituted and strengthened. Collaborated efforts of law-enforcement, healthcare industry, and infection control personnel are mandated to integrate surveillance, legislation, industrial, and marketing audit. 


\section{Research}

Microbiological research on the mechanisms, dynamics, and drivers of spread of AMR, behavioural research on non-adherence to prescribed drug schedules and selfmedication, and pharmacological research for development of newer antimicrobials and traditional medicines need to be undertaken under Governmental sponsorship in the wake of decline in industry sponsored research.

\section{Regional Level}

Regional cooperation is pivotal to restrict the spread of AMR. The Jaipur declaration on AMR-2011 for SEAR and the Chennai declaration for India are efforts to this end (43, 70). The control of AMR calls for institution of intergovernmental organizations focused on health similar to existing bodies for finance, trade, regional-cooperation, development, human rights, and environment. Discussions on AMR can be furthered in regional summits of existing bodies such as association of south-east asian nations (ASEAN), south Asian association for regional cooperation (SAARC), gulf cooperation council (GCC), European Union (EU), African Union, Union of South American Nations, etc. in the interim period.

\section{Global Level}

WHO is engaged in guiding the response to AMR through policy guidance, support for surveillance, technical assistance, knowledge generation and partnerships, and laboratory quality assurance. WHO has issued a call for action to halt the spread of AMR by introducing a sixpoint policy package for all countries to combat AMR. This includes commitment to a comprehensive, financed national plan with accountability and civil society engagement, strengthening of surveillance and laboratory capacity, ensuring uninterrupted access to essential medicines of assured quality, regulation and promotion of rational use of medicines, for instance in animal husbandry, and ensuring proper patient care, reduction of usage of antimicrobials in food-producing animals, enhancing infection prevention and control, and fosterage of innovations, and research to develop new tools (2). WHO has also laid down the procedure to establish national laboratory-based surveillance including identification of pathogens and diseases of public health importance, creation of network of Antimicrobial susceptibility testing and standardization of involved methodologies (71). WHO has classified antimicrobials into key access, watch group, and reserve group to optimize usage guidelines worldwide (72). WHO has also advocated a priority pathogens list in 2017 to highlight a list of bacteria for which newer antimicrobials are urgently required (73).

World bodies such as Association for Prudent use of antimicrobials (APUA) and World alliance against antibiotic resistance (WAAR) are efforts to this end (74). Various policies have been included in the national policy of many countries; however, there is a wide scope for improvement towards implementation.

\section{Conclusions}

AMR is rising in alarming proportions worldwide, thereby threatening the advances made towards public health security of the world. There is a dire need to identify this threat, develop concerted multipronged strategy, develop infrastructure, foster expertise, and take coordinated and urgent steps to tackle the serious public health challenge. It is time for action; otherwise, we will face the consequences of microbial genocide of humankind. Resolute conviction towards astute measures with a sustained momentum will hold a promise for safeguarding health of future generations.

\section{Footnotes}

Authors' Contribution: The author was the clinical microbiologist investigating the patients.

Ethical Approval: The patient consent and ethical approval were covered by the institutional committee.

Funding/Support: None.

Conflicts of Interest: None.

\section{References}

1. Khan ID, Sahni AK, Bharadwaj R, Lall M, Jindal AK, Sashindran VK Emerging organisms in a tertiary healthcare set up. Med J Armed Forces India. 2014;70(2):120-8. doi: 10.1016/j.mjafi.2013.09.005. [PubMed: 24843199].

2. World Health Organization . World Health Day 2011: policy briefs Geneva: WHO; 2017. Available from: http://www.who.int/worldhealth-day/2011/policybriefs/en/index.html.

3. Jindal AK, Pandya K, Khan ID. Antimicrobial resistance: A public health challenge. Med J Armed Forces India. 2015;71(2):178-81. doi: 10.1016/j.mjafi.2014.04.011. [PubMed: 25859082].

4. Khan ID, Sahni AK. Bacterial infections and emerging resistance in renal transplant recipients. Bangladesh J Med Sci. 2015;14(1):14.

5. Khan ID, Lall M, Sen S, Ninawe SM, Chandola P. Multiresistant Elizabethkingia meningoseptica infections in tertiary care. Med $J$ Armed Forces India. 2015;71(3):282-6. doi: 10.1016/j.mjafi.2014.02.002. [PubMed: 26288498].

6. Keene DD, Penn-Barwell JG, Wood PR, Hunt N, Delaney R, Clasper J, et al. Died of wounds: a mortality review. J R Army Med Corps. 2016;162(5):355-60. doi: 10.1136/jramc-2015-000490. [PubMed: 26468431]. 
7. Danish Khan I. Grenade Explosion Leading to Penetrative Brain Trauma and Demise of Three Children during High Altitude Counter Insurgency Operations. J Arch Mil Med. 2016;4(4) doi: $10.5812 / j a m m .44324$.

8. Khan ID, Basu A, Trivedi S, Prasad M, Rappai TJ, Narayanan RV, et al. Battlefield, bullets and bugs: the vicious circle in gunshots.J Basic Clin Med. 2016;5(1).

9. Vento TJ, Cole DW, Mende K, Calvano TP, Rini EA, Tully CC, et al. Multidrug-resistant gram-negative bacteria colonization of healthy US military personnel in the US and Afghanistan. BMC Infect Dis. 2013;13:68. doi: 10.1186/1471-2334-13-68. [PubMed: 23384348].

10. Khan ID. . Himalayan Wolf Attack on a Twelve Year Old at High Altitude. J Arch Mil Med. 2012;4(4):e44537. .

11. Khan ID, Mukherjee T, Gupta S, Haleem S, Sahni AK, Banerjee S, et al. Ochrobactrum Anthropi Sepsis in Intensive Tertiary Care. J Basic Clin Med. 2014;3(1).

12. Vijayvergia V, Sahni AK, Lal M, Vijay K, Khan ID. Phenotypic detection of ESBL and Amp C Beta-Lactamases in a tertiary care hospital. Bang J Med Sci. 2013;12(4):378-84.

13. Khan ID, Sati A, Arif S, Mehdi I, Bhatt P, Jain V, et al. Streptococcus Mitis/Oralis Corneal Ulcer After Corneal Transplantation.JBasic Clin Med. 2016;5(1).

14. Infectious Diseases Society of America . Bad bugs, no drugs: as antibiotic discovery stagnates, a public health crisis brews. Alexandria: Infectious Diseases Society of America; 2004

15. Sheu TG, Fry AM, Garten RJ, Deyde VM, Shwe T, Bullion L, et al. Dual resistance to adamantanes and oseltamivir among seasonal influenza A(H1N1) viruses: 2008-2010. J Infect Dis. 2011;203(1):13-7. doi: 10.1093/infdis/jiq005. [PubMed: 21148491].

16. Fraser GL, Stogsdill P, Dickens JJ, Wennberg DE, Smith RJ, Prato BS. Antibiotic optimization. An evaluation of patient safety and economic outcomes. Arch Intern Med. 1997;157(15):1689-94. [PubMed: 9250230].

17. Pelletier LJ. Hospital usage of parenteral antimicrobial agents: a gradated utilization review and cost containment program. Infect Control. 1985;6(6):226-30. [PubMed: 3848420].

18. Bozdogan B, Esel D, Whitener C, Browne FA, Appelbaum PC. Antibacterial susceptibility of a vancomycin-resistant Staphylococcus aureus strain isolated at the Hershey Medical Center.J Antimicrob Chemother. 2003;52(5):864-8. doi: 10.1093/jac/dkg457. [PubMed: 14563898].

19. Hidron AI, Edwards JR, Patel J, Horan TC, Sievert DM, Pollock DA, et al. NHSN annual update: antimicrobial-resistant pathogens associated with healthcare-associated infections: annual summary of data reported to the National Healthcare Safety Network at the Centers for Disease Control and Prevention, 2006-2007. Infect Control Hosp Epidemiol. 2008;29(11):996-1011. doi:10.1086/591861. [PubMed:18947320].

20. Albrich WC, Monnet DL, Harbarth S. Antibiotic selection pressure and resistance in Streptococcus pneumoniae and Streptococcus pyogenes. Emerg Infect Dis. 2004;10(3):514-7. doi:10.3201/eid1003.030252. [PubMed: 15109426].

21. Johnson S, Samore MH, Farrow KA, Killgore GE, Tenover FC, Lyras D, et al. Epidemics of diarrhea caused by a clindamycin-resistant strain of Clostridium difficile in four hospitals. NEngl JMed. 1999;341(22):164551. doi: 10.1056/NEJM199911253412203. [PubMed: 10572152].

22. Yong D, Toleman MA, Giske CG, Cho HS, Sundman K, Lee K, et al. Characterization of a new metallo-beta-lactamase gene, bla(NDM-1), and a novel erythromycin esterase gene carried on a unique genetic structure in Klebsiella pneumoniae sequence type 14 from India. Antimicrob Agents Chemother. 2009;53(12):5046-54. doi: 10.1128/AAC.0077409. [PubMed: 19770275].

23. Falagas ME, Bliziotis IA, Kasiakou SK, Samonis G, Athanassopoulou P, Michalopoulos A. Outcome of infections due to pandrug-resistant (PDR) Gram-negative bacteria. BMC Infect Dis. 2005;5:24. doi: 10.1186/1471-2334-5-24. [PubMed: 15819983].

24. Briusov PG, Frantsuzov VN, Novozhilov AA. [Modern aspects of wound sepsis in war surgical trauma]. Khirurgiia (Mosk). 1999(10):35-8. [PubMed: 10540551].
25. Consunji RJ, Serrato Marinas JP, Aspuria Maddumba JR, Dela Paz DJ. A profile of deaths among trauma patients in a university hospital: the Philippine experience. J Inj Violence Res. 2011;3(2):85-9. doi: 10.5249/jivr.v3i2.39. [PubMed: 21498971].

26. Hospenthal DR, Crouch HK, English JF, Leach F, Pool J, Conger NG, et al. Multidrug-resistant bacterial colonization of combatinjured personnel at admission to medical centers after evacuation from Afghanistan and Iraq. J Trauma. 2011;71(1 Suppl):S52-7. doi: 10.1097/TA.0b013e31822118fb. [PubMed: 21795879].

27. Scott P, Deye G, Srinivasan A, Murray CK, Moran K, Hulten E, et al. An outbreak of multidrug-resistant Acinetobacter baumanniicalcoaceticus complex infection in the US military health care system associated with military operations in Iraq. Clin Infect Dis. 2007;44(12):1577-84.

28. Murray CK, Yun HC, Griffith ME, Thompson B, Crouch HK, Monson LS, et al. Recovery of multidrug-resistant bacteria from combat personnel evacuated from Iraq and Afghanistan at a single military treatment facility. Mil Med. 2009;174(6):598-604. [PubMed: 19585772].

29. Calhoun JH, Murray CK, Manring MM. Multidrug-resistant organisms in military wounds from Iraq and Afghanistan. Clin Orthop Relat Res. 2008;466(6):1356-62. doi: 10.1007/s11999-008-0212-9. [PubMed: 18347888].

30. Chen HP, Chen TL, Lai CH, Fung CP, Wong WW, Yu KW, et al. Predictors of mortality in Acinetobacter baumannii bacteremia. J Microbiol Immunol Infect. 2005;38(2):127-36. [PubMed: 15843858].

31. Center for Disease Control and Prevention (CDC) . Preview. MMWR. 2004;53(45).

32. Dallo SF, Weitao T. Insights into acinetobacter war-wound infections, biofilms, and control. Adv Skin Wound Care. 2010;23(4):169-74. doi: 10.1097/01.ASW.0000363527.08501.a3. [PubMed: 20299843].

33. Camp C, Tatum OL. A Review ofAcinetobacter baumanniias a Highly Successful Pathogen in Times of War. Lab Med. 2010;41(11):649-57. doi: 10.1309/lm90ijndddwri3re.

34. Udwadia ZF. MDR, XDR, TDR tuberculosis: ominous progression. BMJ Publishing Group Ltd; 2012.

35. Mahadev B, Kumar P, Agarwal SP, Chauhan LS, Srikantaramu N. Surveillance of drug resistance to anti-tuberculosis drugs in districts of Hoogli in West Bengal and Mayurbhanj in Orissa. Indian J Tuberc. 2005;52(1):5-10.

36. Migliori GB, De Iaco G, Besozzi G, Centis R, Cirillo DM. First tuberculosis cases in Italy resistant to all tested drugs. Euro surveill. 2007;12(5):E070517.

37. Velayati AA, Masjedi MR, Farnia P, Tabarsi P, Ghanavi J, ZiaZarifi $\mathrm{AH}$, et al. Emergence of new forms of totally drug-resistant tuberculosis bacilli: super extensively drug-resistant tuberculosis or totally drug-resistant strains in iran. Chest. 2009;136(2):420-5. doi: 10.1378/chest.08-2427. [PubMed: 19349380].

38. Singla R, Sarin R, Khalid UK, Mathuria K, Singla N, Jaiswal A, et al. Seven-year DOTS-Plus pilot experience in India: results, constraints and issues. Int JTuberc Lung Dis. 2009;13(8):976-81. [PubMed: 19723377].

39. Maude RJ, Pontavornpinyo W, Saralamba S, Aguas R, Yeung S, Dondorp AM, et al. The last man standing is the most resistant: eliminating artemisinin-resistant malaria in Cambodia. MalarJ. 2009;8:31. doi: 10.1186/1475-2875-8-31. [PubMed: 19228438].

40. Pillay D, Zambon M. Antiviral drug resistance. BMJ. 1998;317(7159):660-2. [PubMed: 9728000].

41. Abraham EP, Chain E. An enzyme from bacteria able to destroy penicillin. Nature. 1940;146:837.

42. Lesho E, Craft D, Kirkup BC, Waterman PE, Summers A, Vahey MT, et al. Surveillance, characterisation, and preservation of multidrugresistant bacteria. Lancet Infect Dis. 2011;11(1):8-10. doi: 10.1016/s14733099(10)70261-9.

43. World Economic Forum . Report on Global Risks Geneva: WEF; 2017. Available from: http://qfc.de/qfc.de/uploads/media/ WEFGlobalRisks_Report_2013Teil2.pdf. 
44. Spellberg B, Guidos R, Gilbert D, Bradley J, Boucher HW, Scheld WM, et al. The epidemic of antibiotic-resistant infections: a call to action for the medical community from the Infectious Diseases Society of America. Clin Infect Dis. 2008;46(2):155-64. doi: 10.1086/524891. [PubMed: 18171244].

45. Centers for Disease Control and Prevention . Bioterrorism Overview 2008. Available from: http://www.cdc.gov.

46. Khan ID. Challenges and Opportunities in Diagnosis and Management of Infectious Diseases in Developing Country Healthcare System.J Basic Clin Med. 2016;5(1).

47. Bhatia R, Narain JP. The growing challenge of antimicrobial resistance in the South-East Asia Region-are we losing the battle? Indian J Med Res. 2010;132:482-6. [PubMed: 21149995].

48. Centre for Disease Control and Prevention . Guidelines for Hand Hygiene in Healthcare Settings 2017. Available from: https://www.cdc. gov/infectioncontrol/guidelines/hand-hygiene/index.html.

49. Centre for Disease Control and Prevention . Environment Infection Control Guidelines 2017. Available from: https://www.cdc.gov/ infectioncontrol/guidelines/environmental/index.html.

50. Khan ID, Gupta N, Rangan NM, Singh R, Sharma AK, Khurana A, et al. Evaluation of pre and post analytical variables in clinical microbiology services in multidisciplinary icu of a medical college and tertiary care hospital. J Basic Clin Med. 2016;5(1).

51. Chang MT, Wu TH, Wang CY, Jang TN, Huang CY. The impact of an intensive antimicrobial control program in a Taiwanese medical center. Pharm World Sci. 2006;28(4):257-64. doi:10.1007/s11096-006-90355. [PubMed: 17066241].

52. Apisarnthanarak A, Danchaivijitr S, Khawcharoenporn T, Limsrivilai J, Warachan B, Bailey TC, et al. Effectiveness of education and an antibiotic-control program in a tertiary care hospital in Thailand. Clin Infect Dis. 2006;42(6):768-75. doi:10.1086/500325. [PubMed:16477551].

53. Khan ID, Basu A, Kiran S, Trivedi S, Pandit P, Chattoraj A. DeviceAssociated Healthcare-Associated Infections (DA-HAI) and the caveat of multiresistance in a multidisciplinary intensive care unit. Med Armed Forces India. 2017;73(3):222-31. doi: 10.1016/j.mjafi.2016.10.008.

54. Sahu C, Konar J, Banerjee S, Pal S, Khan ID. Nasal carriage of MRSA amongst health care workers in a tertiary care hospital. Int J Curr Med Pharma Res. 2015.

55. National Centre for Disease Control . Revised Hospital Infection Prevention and Control Guidelines. Ministry of Health and Family Welfare, Govt of India; 2017.

56. Australian Commission on Safety and Quality in Healthcare . Healthcare Associated Infections Consumer Factsheet. ; 2017

57. Centre for Disease Control and Prevention . Guidelines for Isolation Precautions: Preventing Transmission of Infectious Agents in Healthcare Settings. ; 2007.

58. Centre for Disease Control and Prevention . Guidelines for Hand Hygiene in Healthcare Settings. ; 2017.

59. Centre for Disease Control and Prevention . Guidelines for Multidrug- resistant organisms (MDRO) Management. ; 2017

60. Centre for Disease Control and Prevention . Guidelines for Infection Control in Healthcare personnel. ; 2017.

61. Centre for Disease Control and Prevention . Updated CDC recommendations for the management of Hepatitis B virus-infected health-care providers and students. ; 2017.

62. Centre for Disease Control and Prevention. Updated US Public Health Service guidelines for the management of occupational exposures to HIV and recommendations for postexposure prophylaxis. ; 2017.

63. Chandrasekera RM, Lesho EP, Chukwuma U, Cummings JF, Waterman PE. The state of antimicrobial resistance surveillance in the military health system: a review of improvements made in the last 10 years and remaining surveillance gaps. Mil Med. 2015;180(2):145-50. doi: 10.7205/MILMED-D-14-00297. [PubMed: 25643381].

64. Katz R, Fischer J. The Revised International Health Regulations: A Framework for Global Pandemic Response.;

65. Bywater R, McConville M, Phillips I, Shryock T. The susceptibility to growth-promoting antibiotics of Enterococcus faecium isolates from pigs and chickens in Europe. J Antimicrob Chemother. 2005;56(3):53843. doi: 10.1093/jac/dki273. [PubMed: 16085669].

66. NNIS System . National Nosocomial Infections Surveillance (NNIS) System report Atlanta: Centers for Disease Control and Prevention, Department of Health and Human Services; 2004. Available from: http://www.cdc.gov.

67. Moh.gov . Ministry of Health and Family Welfare, Govt of India. National Health Policy; 2017.

68. World Health Organization . Antimicrobial resistance: revisiting the "tragedy of the commons" 2017. Available from: http://www.who.int/ bulletin/volumes/88/11/10-031110/en/index.html.

69. National Centre for Disease Control . National Treatment Guidelines for Antimicrobial Use in Infectious Diseases Govt of India.; 2017. Available from: www.ncdc.gov.in/mainlinkfile/file571.

70. Ghafur A, Mathai D, Muruganathan A, Jayalal JA, Kant R, Chaudhary D, et al. The Chennai Declaration: a roadmap to tackle the challenge of antimicrobial resistance. Indian J Cancer. 2013;50(1):71.

71. Bhalwar R, Jindal AK, Vaidya R, Nandraj S. Standard Treatment Guidelines: Medical Management and Costing of Select Conditions. AFMC Pune; 2007.

72. World Health Organization . WHO Model List of Essential Medicines 2017. Available from: http://www.who.int/medicines/publications/ essentialmedicines/en/.

73. World Health Organization. Global priority list of antibiotic-resistant bacteria to guide research, discovery and development of new antibiotics 2017. Available from: http://www.who.int/mediacentre/news/ releases/2017/bacteria-antibiotics-needed/en/.

74. Carlet J, Rambaud C, Pulcini C, Waar ISOTACLDDBM. WAAR (World Alliance against Antibiotic Resistance): Safeguarding antibiotics. An timicrob Resist Infect Control. 2012;1(1):25. doi: 10.1186/2047-2994-1-25. [PubMed: 22958542]. 